\title{
Rede universitária da Rota de Intergração Latino-Americana: um sobrevoo sobre questões emergentes do Corredor Bioceânico
}

DOI: http://dx.doi.org/10.20435/inter.v20iespecial.2638

Iniciamos esta apresentação, convidando o leitor, a apreciar a letra da música "o condor passa".

\section{O CONDOR PASSA}

Eu preferiria ser um condor a ser um caracol

Sim, eu preferiria, se eu pudesse, eu certamente preferiria

Hum Huum

Eu preferiria ser um martelo a ser um prego

Sim, eu preferiria, se eu somente pudesse, eu certamente preferiria

Hum Huum

Longe, eu preferiria velejar longe

Como um cisne que está aqui e desaparece

Um homem fica preso à coroa

Ele dá o mundo

É o mais triste som

É o mais triste som

Hum Huum Hum Huum

Eu preferiria ser uma floresta a ser uma rua

Sim, eu preferiria, se eu pudesse, eu certamente preferiria

Eu preferiria sentir a Terra abaixo dos meus pés

Sim, eu preferiria, se eu somente pudesse, eu certamente preferiria

Longe, eu preferiria velejar longe

Como um cisne que está aqui e desaparece

Um homem fica preso à coroa

Ele dá o mundo

É o mais triste som

É o mais triste som

Hum Huum Hum Huum

Hum Huum Hum Huum

(Julio de La Paz)

A escolha de uma música para começar o percurso retórico deste texto não se deu de forma aleatória. A mais de cinco mil pés de altitude durante a expedição do grupo da RILA na cordilheira dos Andes, temperatura fria de cinco graus, rumo ao até então, para nós, desconhecido deserto do Atacama.

Nessa trajetória, desde que saímos da cidade de Campo Grande, início do Corredor Bioceânico, já havíamos percorrido mais de dois mil km. O grupo das vinte e oito caminhonetes de Rileiros, como éramos chamados, contemplamos paisagens incríveis: o cerrado, o Pantanal, as montanhas de Sete Cores após a cidade de Jujuy e finalmente estávamos na Cordilheira dos Andes, prestes a chegar no deserto do Atacama rumo aos Portos do Chile. Em companhia do nosso amigo, in memoriam, Prof. Dr. Roberto Paixão, viajando juntos no carro, tivemos a oportunidade de informalmente assistirmos uma aula de Geografia física, ao som da música O condor passa. Durante o percurso, um pouco desconfortáveis devido os efeitos da altitude da Cordilheira dos Andes, nosso amigo nos dizia: "meu sonho era dirigir na Cordilheira dos Andes ouvindo minha música favorita". 
Destacamos, então, o sonho. Essa era uma palavra que recorrentemente ouvíamos das pessoas simples dos pequenos povoados por onde éramos calorosamente recepcionados- uma das mais marcantes foi a cidade de Carmelho Peralta- crianças cantando no coreto da praça e as matulas feitas de chipa e sopa paraguaia feitas que recebíamos ao nos despedirmos da população em sinal de gratidão e esperança no progresso que estava por vir há tempos. Ouvíamos, ainda, a palavra "sonhos" nas reuniões políticas e nas palavras dos empresários. Uma das frases mais marcantes foi: "a Rota Bioceância não representa apenas um sonho, mas uma realidade". Essa realidade se traduz muito além dos aspectos econômicos. Representa um deslocamento de olhares para lugares de fronteiras invisíveis, de potencialidades e oportunidades das mais diversas esferas. Voltemos a apreciar mais um pouco algumas passagens da letra da música:

Eu preferiria ser um condor a ser um caracol

Sim, eu preferiria, se eu pudesse, eu certamente preferiria

Eu preferiria ser um martelo a ser um prego

Sim, eu preferiria, se eu somente pudesse, eu certamente preferiria

Eu preferiria ser uma floresta a ser uma rua

Sim, eu preferiria, se eu pudesse, eu certamente preferiria

Eu preferiria sentir a Terra abaixo dos meus pés

Sim, eu preferiria, se eu somente pudesse, eu certamente preferiria

Longe, eu preferiria velejar longe

Como um cisne que está aqui e desaparece [...].

Talvez para alguns leitores, a letra possa trazer uma sensação de nostalgia. Para alguns a música pode representar opressão (martelo e prego), desespero, liberdade (se eu pudesse, preferencia por algo que não se tem). Pode-se-ia, ainda, perceber relações dicotômicas entre floresta e rua- relacionados aos aspectos de globalização, modernidade e impacto econômico. Interpreta-se-ia, ainda, aspectos antagônicos como caracol/pés/rua (fragilidade/fixidez, progresso) martelo/floresta/condor (força/punição/pouco explorado/liberdade). Todos esses aspectos são heteroglóssicos e polissêmicos e, portanto, passíveis de outras interpretações.

Nesse sentido, convidamos o leitor a ressignificá-los e estabelecer outros pensamentos rizomaticos com relação ao Projeto do Corredor Bioceânico. Destacamos o papel importante da universidades que compõem a UNIRILA que conhecem as realidades do seus territórios dos quatro países. Semelhantemente às metáforas da letra da música, aspectos como progresso/ exploração, turismo/exploração sexual infantil, desenvolvimento local, integração, empreendedorismo, entre outros, são aspectos cujas universidades possuem expertise de pesquisadores que podem contribuir para mitigar ou fomentar por intermédio de estudos colaborativos em rede.

Feitas tais considerações, convidamos vocês leitores a serem condors e por intermédio dessa metáfora possam sobrevoar os textos aqui apresentados. Os autores fornecem um panorama da abrangência das possibilidades de pesquisas relacionados ao Corredor Bioceânico. Os trabalhos visam fornecer informações técnico-científicas que poderão auxiliar projetos inovadores envolvendo os setores governamentais, acadêmicos e empresariais. Apresentamos, a seguir, as seguintes temáticas, seguidas dos respectivos autores.

O artigo de abertura intitulado Turismo como instrumento dinamizador do Corredor Rodoviário Bioceânico, em que João Carlos Parkinson de Castro versa que o turismo possui grande potencial para acelerar o crescimento econômico por meio do Corredor Rodoviário Bioceânico, que conectará o Atlântico ao Pacífico cruzando Brasil, Paraguai, Argentina e Chile, desde Porto Murtinho, no Centro Oeste do Brasil, até Antofagasta, no norte do Chile. Com boa gestão e a 
governança apropriada, o turismo pode gerar empregos de qualidade e reduzir a pobreza, bem como criar incentivos para a proteção ambiental. A promoção do turismo ao longo do Corredor Rodoviário também pode ser um instrumento para uma transição gradual em direção a uma economia mais inclusiva, resiliente e sustentável. As mudanças esperadas, no entanto, dependem não apenas da instalação de uma infraestrutura moderna. O sucesso estará condicionado ao desenvolvimento de parcerias público-privadas, envolvendo os diversos atores interessados, à integração de empresas do setor de turismo a empresas de outros setores ao longo da cadeia de valor, à melhoria da produção de estatísticas e análises setoriais, bem como à educação e treinamento vocacional, com o apoio das universidades locais. Os tomadores de decisão precisam entender que resultados positivos serão mais facilmente atingidos se todos os países unirem esforços e garantirem o uso sustentável dos ecossistemas. Por fim, apesar das atuais restrições orçamentárias, é possível avançar explorando mecanismos de financiamento inovadores e garantindo o uso efetivo das capacidades das universidades e do setor privado.

O segundo artigo, Desafios para o Corredor Bioceânico e suas potencialidades turísticas: a questão da livre circulação de pessoas, de José Roberto da Silva Lunas, Aline Santos Melo e Maria Cristiane Fernandes da Silva Lunas, discute como a pesquisa explora os desafios da livre circulação de pessoas para fins turísticos com a implantação do corredor bioceânico que ligará Chile, Argentina, Paraguai e Brasil. A pesquisa realizou-se por meio de levantamento bibliográfico e documental, e entrevista a operadores de turismo e viajantes. Os resultados revelam entraves existentes para a circulação de pessoas nesses países, que poderão se reproduzir no trecho previsto para o corredor, e apontam a necessidade de se estabelecer novos acordos aumentem o conforto e a segurança dos turistas no corredor.

O terceiro artigo, Rota de Integração Latino-Americana (RILA) para o desenvolvimento turístico, dos autores Thiago Andrade Asato, Michel Constantino, Arlinda Cantero Dorsa e Milton Augusto Pasquotto Mariani, discorre sobre a Rota de Integração Latino-Americana (RILA) ou Rota Bioceânica, fomentando como tal rota pode contribuir para o desenvolvimento local de Mato Grosso do Sul e, consequentemente, dos países que permeiam o trajeto completo do corredor, no olhar voltado ao desenvolvimento turístico. A pesquisa pautou-se de entrevistas semiestruturadas direcionadas aos gestores que participaram da caravana de teste da II Rota de Integração Latino-Americano (denominada RILA), realizada em agosto de 2017.

O quarto artigo, Fluxos turísticos entre os países do Corrredor Bioceânico, de Michel Constantino, Arlinda Cantero Dorsa, João Carlos Medeiros de Aragão e Dany Rafael Fonseca Mendes, tem por objetivo analisar o fluxo de turistas entre os países da Rota Bioceânica. Neste estudo, uma análise quantitativa foi utilizada para investigar a demanda internacional de turismo entre o Brasil, Argentina, Paraguai e Chile. Como a Rota Bioceânica ainda é uma aspiração em construção, a literatura é escassa e esse estudo se apresenta como pioneiro. Os resultados indicam que as variáveis tradicionais de demanda, chegada de turistas, formas de viagem, eventos internacionais e chegadas em Mato Grosso do Sul apresentaram um panorama geral do fluxo, que se revela incipiente e com pouca integração entre os países. A criação da Rota Bioceânica pode contribuir para o desenvolvimento dos países, principalmente na área de turismo que é dinâmico e crescente no mundo, e ainda pouco explorado na América do Sul.

O quinto artigo, Brasil, Paraguai, Argentina e Chile / Rota Bioceânica: relações culturais no território vivido, das pesquisadoras Edilene Maria Oliveira, Maria Augusta Castilho e Magali Lúzio Ferreira tem como objeto de estudo os países da América Platina envolvidos na Rota Bioceânica 
e suas relações culturais de vizinhança. O estudo analisa as culturas materiais e imateriais que permeiam este espaço e seus entrelaçamentos na conexão entre o Centro-Oeste brasileiro e o Pacífico. Assim, não basta o foco sobre as questões logísticas que facilitarão o mercado em geral, o agronegócio, a importação e exportação de produtos, mas sim impulsionar os setores empresariais dos quatro países envolvidos na referida rota. O projeto cria relações de convivências e estreitam as culturas territoriais. Infere-se que a relevância deste trabalho é o de salvaguardar o sentimento de pertença dos cidadãos locais em prol dos direitos de cidadania, por isso, há a necessidade de não se privar a temática como registro a preservação patrimonial. Para a realização do estudo utilizou-se o método dedutivo com uma abrangência sistêmica, por meio de uma investigação criteriosa em arquivos públicos, bibliotecas, livros, jornais, sites, assinalando as obras que fornecerão subsídios ao trabalho em tela. Os resultados apontam evidências que reafirmam e privilegiam a preservação da identidade, história e identificação cidadã.

O sexto artigo, Como os turistas provenientes de países do Corredor Bioceânico "enxergam" os atrativos turísticos de Bonito, MS: uma análise calcada em princípios da netnografia, proposto por Maurílio Barbosa de Oliveira da Silva, Maria Clara de Souza Moreira, Dyego de Oliveira Arruda e Milton Augusto Pasquotto Mariani, objetiva compreender como os turistas do Paraguai, Argentina e Chile "enxergam" os atributos dos atrativos turísticos de Bonito,MS, um importante destino turístico na área de influência da Rota Bioceânica. Para tanto, realizou-se uma pesquisa netnográfica, com o uso do software Iramuteq. Verificou-se que os turistas valorizam os atributos relacionados ao meio ambiente, corroborando a ênfase de Bonito, MS em atividades ligadas ao ecoturismo.

O sétimo artigo, Eixos de integração e desenvolvimento, Rota de Integração Latino-Americana e turismo: território de Mato Grosso do Sul e franjas fronteiriças, da autora Cleonice Alexandre Le Bourlegat propõe uma análise de que a Rota Bioceânica, que ligará o Centro-Oeste brasileiro ao Oceano Pacífico, proporcionará a implementação de intercâmbios econômicos, sociais, turísticos e culturais, conforme declarações de autoridades governamentais, empresários, jornalistas e outros. O presente estudo visa verificar a tônica dos discursos oficiais a respeito de tal Rota, no que tange, principalmente, ao desenvolvimento sustentável e à formação de capital social, considerados fundamentais para a sustentabilidade de empreendimentos como este. Para embasar o estudo, além das discussões acerca do capital social, a partir de Putman, considerou-se relevante pontuar questões presentes na Agenda 2030 da Organização das Nações Unidas para o Desenvolvimento Sustentável, ONU, principalmente ao que se refere ao objetivo número 8, que traz orientações em relação ao crescimento econômico sustentado, inclusivo e sustentável.

O oitavo artigo, Interação e inovação na trajetória do Sistema Turístico de Bonito, MS: um modelo para os destinos da RILA?, dos estudiosos Dores Cristina Grechi, Heros Augusto Santos Lobo e Patrícia Cristina Statella Martins disserta sobre a gestão de destinos turísticos no Brasil vem se transformando à partir do reconhecimento da necessidade de articulação entre os diferentes stakeholders do turismo atuantes em cada localidade. Neste contexto, o presente artigo tem como objetivo central apresentar uma análise do sistema gestor do turismo em Bonito, com ênfase na sua operacionalização por meio do Voucher Único e na criação de leis específicas para o turismo. Pretende também analisar se esse sistema seria aplicável para os destinos que pertencem a Rota de Integração Latino-Americana (RILA). As análises foram realizadas tanto baseadas em revisões teóricas, quanto em estudos-síntese já realizados sobre o destino, com ênfase nos aspectos teóricos relacionados à competitividade e inovação dos sistemas turísticos. Os resultados 
apontam diretrizes importantes para gestão inovadora do destino após duas décadas desde a implantação do Voucher Único, ferramanta de controle de visitantes, criada endogenamente e responsável por organizar a exploração da atividade turística no local.

O nono artigo, Perspectivas do Corredor Bioceânico para o Desenvolvimento Local no estado de MS: o caso de Porto Murtinho, dos pesquisadores Thiago Andrade Asato, Débora Fittipaldi Gonçalves e Erick Pusck Wilke, versa sobre a Rota Bioceânica, fomentando como tal rota pode contribuir para o desenvolvimento local de Mato Grosso do Sul, mais especificamente na cidade de Porto Murtinho, no olhar voltado ao desenvolvimento turístico. O trabalho é fundamentado inicialmente nos impactos da grande obra da ponte binacional entre Porto Murtinho, no Brasil, e a cidade gêmea Carmelo Peralta, no Paraguai. Posteriormente, como fundamentação teórica, trataremos de conceitos de rota para efeito de benchmarking, referendando outras rotas de integração latino-americana como San Juan, La Rioja e Coquimbo. Na parte final do artigo, trataremos de políticas públicas no contexto de MS a partir da viabilidade do corredor bioceânico. A metodologia utilizada será pesquisa bibliográfica, bibliométrica e documental sobre os temas relacionados a temática principal e os resultados são parciais sobre os impactos que a Rota causará no município de Porto Murtinho.

O décimo artigo, Turismo de observação de aves no Chaco: oportunidades e desafios ao Corredor Bioceânico, segmento Brasil / Paraguai, de Simone Mamede, Maristela Benites, Alberto Esquivel, Robert Clay, Geancarlo de Lima Merighi e Cleber José Rodrigues Alho, debate que a região de fronteira entre Brasil e Paraguai, no estado de Mato Grosso do Sul, encontra-se no centro de uma das Rotas Bioceânicas propostas e contempla áreas naturais de Chaco e Pantanal com exuberante biodiversidade. O ecoturismo tem na biodiversidade sua principal fonte de insumos, onde se destaca o turismo de observação de aves. Além de conectar territórios para viabilizar uma cadeia produtiva específica, o corredor logístico pode integrar pessoas e grupos sociais, e criar novas oportunidades de valorização dos ambientes naturais por meio do ecoturismo. O objetivo deste trabalho é propor roteiros integrados para o turismo de observação de aves na fronteira entre Brasil e Paraguai como estratégia de conservação da biodiversidade, inclusão social, dinamização econômica e valorização cultural das comunidades localizadas nos territórios de influência da rota bioceânica. O trabalho foi desenvolvido entre 2002 e 2018 em Porto Murtinho (Brasil), Carmelo Peralta, departamento de Alto Paraguay, Concepción, Presidente Hayes e Boquerón (Paraguai). Foram identificados 10 potenciais roteiros para o turismo de observação de aves, dos quais, cinco encontram-se em Porto Murtinho, dois binacionais (Brasil/ Paraguai), e outros três no Paraguai. Os roteiros envolvem locais com alta diversidade de aves: Parque Natural Municipal da Cachoeira do Apa, Parque Nacional Defensores del Chaco, Parque Nacional Médanos del Chaco, além de Reservas Privadas e a Reserva da Biosfera do Chaco no Paraguai. Ao todo, somam-se mais de 400 espécies de aves, entre endêmicas, migratórias, raras e ameaçadas. Esse segmento turístico representa um dos diversos modelos para o desenvolvimento sustentável da região da Rota Bioceânica. Além disso, a proposta de roteiros integrados de birdwatching no Chaco reflete o potencial transfronteiriço do segmento e pode estimular a melhoria dos destinos, a geração de renda, a identificação de novos produtos e ampliar a qualidade da experiência do turista observador.

O décimo primeiro artigo, Caracterização econômica dos municípios sul-mato-grossenses do Corredor Bioceânico, dos investigadores Michel Constantino, Arlinda Cantero Dorsa, Daniel Silva Boson e Dany Rafael Fonseca Mendes, tem por objetivo caracterizar, a partir de indicadores 
econômicos, os municípios de Mato Grosso do Sul (MS) com influência direta e indireta na criação da Rota Bioceânica, que ligará o Brasil ao Oceano Pacífico. Para a presente análise, foram avaliados todos os municípios, em dois traçados distintos, entre a capital de Mato Grosso do Sul, Campo Grande e Porto Murtinho, cidade sul-mato-grossense que faz fronteira com Paraguai. Os indicadores econômicos utilizados foram: PIB; PIB per capita; população; arrecadação de impostos; valor adicionado bruto setorial; e atividade econômica principal, secundária e terciária. Os resultados trazem evidências não só de desenvolvimento econômico entre 2010 e 2015, como também de diferenças na variação do crescimento de acordo com a atividade produtiva de cada município avaliado. A análise de cluster apresentou municípios com similitudes, e, neste contexto, Campo Grande diverge dos demais municípios, enquanto Maracaju e Sidrolândia formam um cluster único de grande impacto econômico no Estado. Do ponto de vista econômico, Porto Murtinho - apesar do crescimento do setor de turismo no município - é a cidade mais vulnerável, apresentando baixa dinâmica produtiva, com uma economia baseada na pecuária e, ainda, fortemente dependente de recursos da administração pública.

O décimo segundo artigo, Perspectivas da economia criativa e do desenvolvimento local no Corredor Bioceânico, de Thiago Andrade Asato, Heitor Romero Marques, Rodrigo Mussi Buzarquis e Pedro Pereira Borges, de revisão bibliográfica, objetiva caracterizar a Rota Bioceânica na perspectiva da economia criativa e do desenvolvimento local. Tal rota terá 2,2 mil km entre Campo Grande e Antofagasta. No roteiro da Rota denota-se a passagem por 12 cidades. Um tratado já firmado diz respeito a uma ponte ligando Porto Murtinho a Carmelo Peralta no Paraguai. Viés importante é o turístico da Rota. Pela diversidade de atrações nos quatro países, a potencialidade para o desenvolvimento turístico é imensa, o planejamento deve envolver o poder público, setor privado e comunidades locais. A ideia de desenvolvimento corresponde à ação de desvelamento, crescimento, desabrochar de algo, comportando variadas locuções a exemplo de local, social, econômico, político, territorial, comunitário, sustentável, endógeno, exógeno, no local, horizontal, vertical e humano, entre outros. A economia criativa têm sua origem na criatividade individual, habilidade e talento e têm um potencial de riqueza e criação de empregos através da geração e exploração da propriedade intelectual.

O décimo terceiro artigo, Capital social e os desafios do Corredor Bioceânico, de Maria Geralda Miranda, Reis Friede e Katia Avelar aborda sobre a Rota Bioceânica, que ligará o Centro-Oeste brasileiro ao Oceano Pacífico, proporcionará a implementação de intercâmbios econômicos, sociais, turísticos e culturais, conforme declarações de autoridades governamentais, empresários, jornalistas e outros. O presente estudo visa verificar a tônica dos discursos oficiais a respeito de tal Rota, no que tange, principalmente, ao desenvolvimento sustentável e à formação de capital social, considerados fundamentais para a sustentabilidade de empreendimentos como este. Para embasar o estudo, além das discussões acerca do capital social, a partir de Putman, considerou-se relevante pontuar questões presentes na Agenda 2030 da Organização das Nações Unidas para o Desenvolvimento Sustentável, ONU, principalmente ao que se refere ao objetivo número 8, que traz orientações em relação ao crescimento econômico sustentado, inclusivo e sustentável.

O décimo quarto artigo, Transporte rodoviário internacional de cargas perigosas, de José Carlos Taveira, Raphael Ricardo Portela e Rogério Rodolfo Menegante, propõe uma análise das cargas transportadas nos países da América do Sul nas rodovias internacionais, identificando os riscos que podem ocorrer, os quais desencadeiam impactos ao meio ambiente e prejudicam o ecossistema do nosso planeta. São apresentadas as legislações pertinentes ao tema, bem como 
os regulamentos ambientais do Chile, Argentina e Paraguai, e toda a normatização da Associação Brasileira de Normas Técnicas (ABNT) relacionada a esse tema. São identificados, nesse contexto, os equipamentos de proteção individual (EPIs) adequados que devem ser utilizados pelos motoristas, a classificação dos produtos perigosos e os requisitos necessários para o motorista que irá transportá-los. Os resultados destacam as irregularidades no transporte de cargas perigosas, caso não seja feita a mitigação desse problema, por meio do que se apresentam nas considerações finais.

O décimo quinto artigo, Indicadores dos serviços de abastecimento de água e esgotamento doméstico na Rota de Integração Latino-Americana, de Arlinda Cantero Dorsa, Fernando Jorge Corrêa Magalhães Filho e Mariana Antonio de Souza Pereira, produz uma análise de desempenho dos provedores públicos e privados de saneamento inseridos na Rota de Integração Latino-Americana, indica que as empresas privadas superam as públicas em investimentos e produtividade, contudo ambas necessitam de serviços especializados. As correlações existentes entre os indicadores indicam que quanto maior o atendimento do serviço, maior é a tarifa cobrada, e as perdas de água afetam diretamente no faturamento. Apesar dos avanços, ainda há necessidade de melhoria nos serviços.

O décimo sexto artigo, Caracterização ambiental do uso e ocupação do solo das áreas de influência em municípios da Rota de Integração Latino-Americana, de Mariana Antonio de Souza Pereira, Fernando Jorge Corrêa Magalhães Filho, Ana Paula Silva Teles e Fabio Martins Ayres, expõe que a análise ambiental é fundamental para reconhecer as potencialidades e vulnerabilidades da região investigada. Baseado em imagens de satélites, o estudo buscou analisar o uso e a ocupação do solo em municípios que fazem parte do corredor bioceânico localizado no Estado do Mato Grosso do Sul e que também possuem territórios inseridos na Bacia do alto Paraguai. Constatou-se que em média $60 \%$ dos municípios tiveram parte de sua vegetação nativa substituídas por monoculturas e pastagens exóticas.

O décimo sétimo artigo, Porto Murtinho, Mato Grosso do Sul, e o Corredor Bioceânico: caminhos possíveis para a sustentabilidade socioambiental, de Maristela Benites, Simone Mamede, Carla Villamaina Centeno e Gilberto Luiz Alves, cujo objeto é o município de Porto Murtinho, localizado na porção sudoeste de Mato Grosso do Sul, objetiva analisar a economia local e seu reflexo na biodiversidade nas últimas décadas, além de sondar possíveis impactos da implantação da Rota Bioceânica, tendo como pressupostos o desenvolvimento sustentável, o reconhecimento e a valorização da cultura, do ecoturismo, do turismo de observação de aves e da vida selvagem.

O décimo oitavo artigo, $A$ importância do estudo dos impactos sociais junto às comunidades locais dos territórios que integram o Corredor Rodoviário Bioceânico, de Luciane Pinho Almeida, Léia Lacerda Teixeira, Kátia Cristina Nascimento Figueira, visa apresentar a constituição do Grupo de Trabalho "Impactos Sociais" vinculado à Rede Universitária da Rota do Corredor BioceânicoPorto Murtinho - Portos do Norte, Chile. O objetivo da criação desse grupo é o desenvolvimento de um programa de pesquisa e extensão com a finalidade de investigar, diagnosticar as realidades locais, identificar situações de vulnerabilidade e risco sociais vivenciados pelas populações que residem ao longo do território do Corredor Bioceânico Brasil - Paraguai - Argentina - Chile, com a intenção de propor o desenvolvimento de estratégias de enfrentamento dos problemas identificados, a fim de melhorar as condições de vida dessas comunidades. O GT estruturou-se em seis eixos de abordagem com formação de equipes distintas. O recorte geográfico de atuação dos pesquisadores brasileiros será o entorno do percurso que compreende Campo Grande e 
Porto Murtinho até o limite fronteiriço entre Brasil e Paraguai. A etapa inicial das pesquisas prevê a realização de um diagnóstico das comunidades locais atingidas pela construção do Corredor Bioceânico. Espera-se com o desenvolvimento dos trabalhos contribuir com as políticas públicas voltadas às temáticas de direitos humanos e processos de exclusão social.

O décimo nono artigo, Internacionalización Sur-Sur: desafios y potencialidades de la Red Universitaria de la Carretera Bioceánica, dos pesquisadores Ruberval Franco Maciel, Betina Siufi, Felipe Tabilo e Mario Leiva problematiza que o discurso da internacionalização tornou-se um aspecto importante nas políticas de ensino superior em todo o mundo. Os significados associados à internacionalização são genéricos e podem ter diferentes conotações de país para país. Em geral, algumas definições levam em conta as tendências neoliberais e valorizam os saberes e as ciências eurocêntricas e do norte global. As políticas de financiamentos em pesquisas também priorizaram a colaboração internacional com universidades do norte global e incentivaram particularmente a colaboração com as dos países de língua inglesa. Por outro lado, o pensamento abissal tem sido questionado, particularmente a partir de teorias pós-coloniais e políticas críticas de internacionalização. Como contra-discurso, os autores buscam discutir a formação de uma rede universitária envolvendo quatro países latino-americanos: Argentina, Brasil, Chile e Paraguai. Tal iniciativa resulta da interlocução dos Ministérios de Relações Exteriores dos quatro países junto aos grupos de trabalho (governo, setor privado) e se deu em função de um projeto de governo relacionado aos trabalhos que deram suporte à implementação da Rota Bioceânica que ligará Campo Grande no Brasil aos portos do norte do Chile nas cidades de Antofagasta e Iquique. $O$ projeto, em sua implementação, poderá inicialmente representar duas grandes oportunidades para os pesquisadores da Rede Universitária. Primeiro, a interlocução com os setores privados e governamentais na promoção de pesquisas que analisem os impactos nos contextos transnacionais, bem como promover a integração entre os pesquisadores de cada território para o enfoque em pesquisas colaborativas.

Boa leitura!

\author{
Ruberval Franco Maciel $^{1}$ \\ Assessor de Relações Internacionais da UEMS \\ Fábio Edir dos Santos Costa ${ }^{1}$ \\ Reitor da UEMS
}

${ }^{1}$ Universidade Estadual de Mato Grosso do Sul (UEMS), Campo Grande, Mato Grosso do Sul, Brasil. 